\title{
The influence of management accountants on managerial decisions
}

\section{Introduction}

In the past decades, the role of the business unit (BU) management accountant or BU controller[1] as the economic conscience of the organization has become increasingly important (Jablonski et al., 1993). More recently, there has been some debate about the allegedly 'new' business-oriented role of controllers. It has been suggested that controllers ought to engage less in 'number crunching' (Vaivio and Kokko, 2006), and extend their involvement in management, as well as their effect on managerial decisions (Burns and Vaivio, 2001). The decentralization of the BU controller position, combined with the increasing centralization of basic accounting systems in organizations (via ERP systems and related consolidation packages), could help in establishing a greater business orientation of BU controllers (Järvenpää, 2007). By acting proactively, controllers might even be able to become full-fledged business partners of their managers (Weißenberger and Angelkort, 2011; Weißenberger et al., 2013).

Whether the aforementioned change to business partnership is actually occurring or whether it is, rather, somewhat of a myth is an issue that has not yet been settled. Although the change does not seem to be manifesting itself as extensively or as quickly as is sometimes thought (De Loo et al., 2011; Wolf et al., 2015), it seems to be progressing nevertheless (De Loo et al., 2011; Goretzki et al., 2013). However, high controller involvement in managerial decisions may not always be desirable or beneficial for an organization (Indjejikian and Matějka, 2006; Maas and Matějka, 2009). It may also not be in the interest of controllers, who do not always desire such a role (Pierce and O'Dea, 2003). This could be due to differences in controllers' personal characteristics (Chang et al., 2014).

These discussions led us to address the following research question: which factors stimulate or hinder BU controllers' influence on managerial decisions taken by their managers? A better understanding of BU controllers' functioning in an organization and the factors impacting on the degree of BU controller influence on managerial decisions could help organizations to structure and/or (re)design the hierarchical positioning of their BU controllers (Merchant and van der Stede, 2012; Chang et al., 2014).

There are several qualitative studies that analyze how controllers interact with their managers in important business matters (e.g., Lambert and Sponem, 2012; Goretzki et al., 2013). In these studies, it is asserted that these interactions are very much context dependent. Some of the elements that seem to play a role in this process include the interpersonal relationship between a controller and his/her manager(s), which is partially determined by their personal characteristics; and organizational and environmental characteristics, such as the financial situation an organization is in, pressure from competitors, or strategic issues that have to be considered. Quantitative studies assessing controllers' degree of involvement in managerial decisions are scarce (Burns and Baldvinsdottir, 2005; Zoni and 
Merchant, 2007; Wolf et al., 2015). In these studies, it has been asserted that there is considerable variance across organizations with respect to the influence controllers have on managerial decisionmaking.

The present study adopts a contingency approach to assess the influence of controllers on managerial decisions (cf. Sathe, 1982; Zoni and Merchant, 2007) and aims to contribute to the extant management accounting literature in a number of ways. First, we try to provide insights on how the BU controller position might be structured to stimulate greater business influence of controllers, whenever this is deemed beneficial for an organization. BU controllers have divided loyalties to their BU manager(s) and the corporate controller(s) they have to report to, which makes them an interesting subject of study (Pierce and O'Dea, 2003; Byrne and Pierce, 2007; Merchant and van der Stede, 2012). Hence, the current study focuses specifically on BU controllers.

Second, we examine the effect of both organizational factors and controllers' personality traits on their influence on managerial decisions. This is done because the organization theory literature, from which the contingency approach evolved, originally discarded the influence of personal characteristics on the functioning of organizations, relying heavily on other contingency variables such as an organization's environment and the information technologies it uses (Byrne and Pierce, 2007). This view has met with increasing criticism (Widener, 2014). We wish to take some of this criticism into account. Our approach is in line with role theory (Katz and Khan, 1978). These authors argue that organizational characteristics, interpersonal relationships, and what they call "attributes of the person" (p. 196), which can be regarded as someone's personal characteristics, jointly determine one's role in an organization. It may therefore be insightful to analyze some of these characteristics in a single study (see also Sathe, 1982).

The remainder of this paper is structured as follows. Section 2 provides the theoretical basis for the empirical model, from which seven hypotheses are developed. Section 3 contains a description of the data used. After listing the results of our empirical analyses in Section 4, we present a discussion and suggestions for future research in Section 5.

\section{Literature}

\section{$2.1 \quad$ Controller influence on managerial decisions}

As was mentioned above, this study focuses on BU controllers. These are "controllers in senior positions, who are responsible for the financial control function on divisions or business unit levels, typically operating between headquarters and the operating company level ... balancing strategic, operating, and financial aspects of control" (Roozen and Steens, 2006, p. 24). BU controllers are often members of BU management teams (Zimmerman, 2014). Consequently, they have to balance two potentially conflicting roles: (1) a support role (helping managers to identify profitable action strategies) and (2) a control role (being responsible for the accuracy of financial reports and the integrity of a BU's internal controls) (Sathe, 1982; Pierce and O'Dea, 2003; Chang et al., 2014). A stronger emphasis on 
one role can reduce the effectiveness of the other role (Sathe, 1982; Maas, 2006; Byrne and Pierce, 2007). Role behavior thus seems to differ when it comes to providing business support vis-à-vis controlling a business unit.

The extent to which controllers fulfill their support role is defined by Sathe (1982, p. 10) as "controller involvement in management". Controller involvement in management is interpreted as the way in which controllers participate in operational and strategic business decision-making. Unfortunately, Sathe did not provide a clear operationalization of the controller involvement in management concept. Such an operationalization has been provided by Matějka (2002). Even though he operationalized controller involvement in management in a valid way, his operationalization solely focused on controller influence on managerial decisions. Some controllers might be involved in decision-making without having any influence on what their managers do, as Argyris (1952) showed in a budget participation setting. Involvement without influence is called "pseudo-participation" (Brownell, 1983, p. 309). Matějka (2002) seems to assume that controller influence and involvement can be equated. We claim that influence is part of involvement but cannot be treated as a substitute, because of the possible presence of pseudo-participation. Since we wanted to stick to the extant literature as closely as possible, we decided to use the aforementioned operationalization, accepting that by so doing, controller influence is emphasized rather than controller involvement. The inferences we draw about controller influence hold for controller involvement as well, but there may be additional factors affecting involvement that we cannot uncover when we adhere to Matějka's (2002) interpretation of influence and involvement.

Another and related issue is that since the controller's viewpoint is taken as the study's point of departure (cf. Zoni and Merchant, 2007), it is debatable whether controllers' impressions of their influence on managerial decisions can be equated with their actual influence[2]. For this reason, we will refer to what we are going to assess as perceived controller influence in management.

\section{$2.2 \quad$ Personality traits}

Many approaches are available to describe and analyze people's personality traits (Digman, 1990; Furnham et al., 2009). Researchers have introduced personality theories which try to reduce personality traits to several predispositions that are assumed to hold throughout a person's life. Among others, this has resulted in the Five Factor ("Big Five") Model, which has become one of the most widely used and extensively researched models of personality traits in academe (Barrick et al., 2001). The Big Five Model assumes that most individual differences in personality can be assigned to the following five sets of traits (Gosling et al., 2003, p. 506): (1) extraversion; (2) conscientiousness; (3) emotional stability[3]; (4) agreeableness; and (5) openness to new experiences. Combinations of these sets of traits can be linked with personality profiles and career styles (Howard and Howard, 2001). High (or low) scores on one dimension can be combined with equally high (or low) scores on the other dimensions. In the 
following sections, we will describe how these sets of traits may be interpreted when examining controllers.

\subsubsection{Extraversion}

A person's degree of extraversion pertains to characteristics such as sociability, assertiveness, and positive emotionality (Anderson et al., 2008). People who are extravert are usually jovial, vocal, and focused on interactions with others (Eswaran et al., 2011). Anderson et al. (2008) find a positive relationship between someone's degree of extraversion and his/her influence on colleagues at work, especially in consultancy firms. Moutafi et al. (2007) conclude that extraversion is positively correlated with higher management levels.

We expect that more extravert BU controllers are better able to express themselves. They may, consequently, influence members of a BU management team and/or other colleagues to a larger extent (Roozen and Steens, 2006). Therefore, the following hypothesis can be formulated:

$H 1$. Extraversion is positively related to perceived controller influence on managerial decisions.

\subsubsection{Conscientiousness}

Conscientiousness refers to the degree to which a person tries to reach his/her goals at work. The generally accepted definition of conscientiousness includes a number of different characteristics: competence, orderliness, dutifulness, striving for achievement, self-discipline, and deliberation (Moutafi et al., 2007). Mount et al. (1998) assert that conscientiousness is positively related to job performance for jobs that involve frequent interactions with others, both inside and outside an organization. Anderson et al. (2008) find a positive relationship between someone's conscientiousness and his/her influence on other people's actions in an engineering department, but not in a consultancy firm.

Because controllers have to work with detailed 'facts and figures', which have to be periodically provided and checked (Zimmerman, 2014), we surmise that they have to be highly disciplined to do their job well and become (more) engaged in managerial decision-making. We expect that BU controllers need a focused and ordered attitude for this to happen. Therefore, we hypothesize the following:

H2. Conscientiousness is positively related to perceived controller influence on managerial decisions.

\subsubsection{Emotional stability}

Emotional stability concerns the degree to which "an individual is secure, stable, relaxed, self-sufficient, not anxious, and tolerant of stress" (Mount et al., 1998, p. 146). Emotionally stable persons react to difficult situations in a calm and steady fashion. People with low emotional stability are viewed as “anxious, insecure, emotional, and tense" (Mount and Barrick, 1998, p. 852). Salgado (1997) suggests that emotional stability can be used as a predictor of job performance for five occupational groups: professionals, policemen, managers, salespersons, and skilled employees. Mount et al. (1998) find a 
positive relation between emotional stability and job performance for jobs involving extensive personal interaction.

We expect that more emotionally stable, rationally acting BU controllers exhibit a greater influence on managerial decision-making, as stated in our third hypothesis:

H3. Emotional stability is positively related to perceived controller influence on managerial decisions.

\subsubsection{Agreeableness}

Agreeableness concerns the degree to which an individual is "cooperative, warm, and agreeable as opposed to cold, disagreeable, and antagonistic" (Salgado, 1997, p. 30). High levels of agreeableness are associated with persons who are "good-natured, flexible, cooperative and want to get along with others by being tolerant and accepting" (Mount et al., 1998, p. 146). Salgado (1997) finds a positive relationship between agreeableness and job performance for professionals, skilled employees, and managers. Mount et al. (1998) argue that there is a positive relation between agreeableness and performance in jobs involving much personal interaction. However, Anderson et al. (2008) do not find that agreeableness affects the influence someone has on (the actions of) other employees in an organization. On the other hand, Eswaran et al. (2011) assert that there is a positive relationship between agreeableness and job involvement.

We expect that more agreeable controllers have less influence on managerial decisions because they are likely to primarily assist their manager, and will therefore relatively easily accept what the latter proposes, instead of engaging in critical discussions with him/her (Byrne and Pierce, 2007). Hence, our fourth hypothesis is formulated as follows:

H4. Agreeableness is negatively related to perceived controller influence on managerial decisions.

\subsubsection{Openness to new experiences}

Openness to new experiences defines "individuals who are creative, curious, and cultured in contrast to people who are practical with narrow interests" (Salgado, 1997, p. 30). The extant literature has not identified a clear relationship between openness and influence. For instance, Anderson et al. (2008) find weak and inconclusive effects between someone's openness and his/her influence on other employees in an organization. Salgado (1997) suggests that a limited relationship exists between these variables, while Mount et al. (1998) identify no clear relationship. Eswaran et al. (2011) paint a different picture, stating that there is a significant, positive relationship between openness and job involvement.

However, Byrne and Pierce (2007) suggest that when controllers, wittingly and explicitly, use new, innovative accounting tools in the creation of information and consequently challenge their managers with unexpected advice, they may be granted a larger role in managerial decision-making (because their prestige among managers increases). Therefore, our fifth hypothesis is defined as follows: $H 5$. Openness is positively related to perceived controller influence on managerial decisions. 


\subsection{Organizational characteristics}

As stated earlier, this study also includes several organizational characteristics that, we believe, impact on a controller's influence on managerial decisions. These characteristics have been mentioned (Sathe, 1982) and studied (e.g., Zoni and Merchant, 2007; De Loo et al., 2011; Wolf et al., 2015) before, but not specifically at the BU level.

\subsubsection{Decentralization}

Decentralization is present when "corporate management assigns decision rights to lower-level managers" (Abernethy et al., 2004, p. 546). In decentralized BUs, corporate managers can reduce their information processing requirements by delegating decision-making rights to lower hierarchical levels in an organization. Corporate management then typically exerts control by relying on financial controls (Merchant and van der Stede, 2012). A BU controller is typically seen as the most appropriate candidate to support financial decision-making, given his/her position in a BU (Zimmerman, 2014). He/she usually has some influence on preparing plans and budgets, challenging operating managers' plans and actions, and participates in a broad range of business decisions (Merchant and van der Stede, 2012). Through decentralization, BU controllers can take on roles that are deemed important by their managers, and extend their influence on managerial decisions (Roozen and Steens, 2006). This leads to the following hypothesis:

H6. The decentralization of decision rights to a BU is positively related to perceived controller influence on managerial decisions.

\subsubsection{Information asymmetry}

Information asymmetry is present when lower-level managers in an organization have specific knowledge that their superiors do not have. In some organizations, BU controllers report directly to their BU managers. When this happens, corporate controllers are likely to have limited access to BU information, so that the level of information asymmetry between a corporate controller and a BU controller is substantial. In other organizations, corporate controllers may supervise BU controllers more directly. In these circumstances, BU controllers will mainly report to corporate staff. Information asymmetry between corporate controllers and BU controllers will be less extreme than in the former situation. In such situations, corporate controllers' supervision can also reduce potential emotional attachments between BU controllers and their operating units, which may further decrease their impact on managerial decision-making (Sathe, 1982; Merchant and van der Stede, 2012).

We expect that controller influence on managerial decisions is large when information asymmetry between BU controllers and corporate controllers is substantial. Therefore, the following hypothesis can be formulated:

H7. Information asymmetry between a BU controller and his/her corporate controller is positively related to perceived controller influence on managerial decisions. 


\subsection{Control variables}

In line with previous studies (Sathe, 1982; Matějka, 2002; Indejikian and Matějka, 2006; Naranjo-Gil et al., 2009; Wolf et al., 2015), the following five control variables have been included:

(1) A BU's last year performance. Poor performance in a previous period is a commonly used indicator of current organizational stress. When an organization enters a stressful period, corporate management often tightens management controls, so that there is less room for a BU controller to influence managerial decisions.

(2) A BU manager's financial knowledge, represented by BU managers' financial education. A financially trained BU manager can have the opportunity to influence a BU controller's views and actions. He/she may then be less likely to accept the latter's advice.

(3) A BU controller's work experience. As a controller's experience in an organization grows, he/she may be less able to embrace and/or evaluate new ideas (quickly), thereby mitigating his/her impact on managerial decisions.

(4) The number of FTEs is a proxy for organizational size. Corporate management typically relies more heavily on BU controllers' expertise with increasing size and complexity of an organization.

(5) Three dummy variables have been included to control for effects related to specific industries: the service sector, the non-profit sector, and financial services. The fourth category (manufacturing and construction companies) is the base category, for which no separate dummy variable has been defined.

Figure I summarizes our research model.

\section{INSERT FIGURE I HERE}

\section{Research method}

\subsection{Sample description}

The data for this study were collected in Dutch organizations by means of surveys administered by parttime Master of Science degree students in Controlling (from a single university). This approach was adopted because surveys make it possible to attract large groups of respondents at relatively low costs (Smith, 2015). All students worked as (junior or assistant) controllers at the time of this study. They were asked to approach BU controllers in their networks who might be willing to participate in the research. Apart from generating high response rates, this approach mitigated potential problems with the understanding of survey items and respondent identification since students could offer concise explanations whenever problems arose. We prepared students for their role in the data collection process in two separate sessions before the survey was spread. We assumed that the respondents they had selected (using two criteria that are introduced below) would be able to answer all questions they would 
be confronted with. However, there were cases in which they could not do this, even after students had offered an explanation of what a particular question entailed. We only included those surveys in which respondents were able to answer all of the questions we wanted to use in our analyses. We also surmised that they provided honest answers. We can therefore assume that key information bias is negligible.

By collecting data in the way we did, we created a convenience sample. This is comparable to what has been done in other, related studies (Byrne and Pierce, 2007; Zoni and Merchant, 2007). A group of BU controllers pre-tested the survey, using pre-test methods that had been proposed by faculty members from the university. These tests were in line with the Three-Step Test-Interview (TSTI) method (Hak et al., 2008). All respondents had to be controllers in BUs that met two conditions: (1) the BU manager of the BU had to have profit responsibility, reporting to a higher level in the organization (such as corporate headquarters); and (2) at least 50 employees (in full-time equivalents/FTEs) had to work in the BU. By so doing, we ensured that BU managers had decision rights in their BU. In total, $119 \mathrm{BU}$ controllers working in 77 different organizations completed the survey. We did not control for firm fixed effects in the sample, which is in line with previous studies (see Zoni and Merchant, 2007, for instance).

In our sample, 57 respondents worked in manufacturing and construction companies (47.9\%), 34 in non-financial services (28.6\%), 19 in financial services (16.0\%), and 7 in the public sector (5.9\%). Only 2 respondents $(1.6 \%)$ did not indicate the sector in which they operated. Because respondents completed the surveys in face-to-face meetings with students, exclusion of incomplete surveys was limited.

Below, we will discuss the measurement of the relevant constructs in this study. All the relevant items, survey questions, item level descriptive statistics, factor analysis results, and indicator loadings are shown in Appendix A. A Harman one-factor test was conducted on all key items relevant for this study (Harman, 1976). The lowest factor loading was 0.003; the highest loading was 0.709. Because a single factor explained $17.7 \%$ of the total variance in all items, we concluded that common method bias was absent. 


\subsection{Measurements}

\subsubsection{Controller influence}

We measured the degree of perceived controller influence on management with an instrument taken from Matějka (2002). This instrument proposes a number of financial measures that BU controllers can typically influence: receivables, inventories, operating expenses, capital expenses, and other benefits that accrue when financial analysis and expertise are brought to bear in business decisions (Sathe, 1982). Matějka (2002) extends Sathe's categorization by including the following items/issues that controllers commonly influence at the BU level: incentive systems, targeted customer segments, and the range of products/services offered. A factor analysis with varimax rotation of Matějka's instrument yielded two factors. The first factor explains $33.4 \%$ of the variance of the underlying items, and the second factor explains $17.2 \%$. The Cronbach's alpha values of these factors are 0.78 and 0.81 , respectively.

One item (capital expenses) was not included in the remainder of our analyses, because it had low loadings on both factors. This result may not be surprising, since capital decisions in an organization are often in the hands of financial managers and risk officers, and are not solely a BU manager's or BU controller's responsibility (Zimmerman, 2014). We distinguished two variables on the basis of the factor analysis: operational perceived influence (OPERPIM) and strategic perceived influence (STRATPIM) on management decisions. OPERPIM (pertaining to the following operating areas: accounts receivable, inventory, and operating expenses) focuses on controller influence on short-term, operational decisions. STRATPIM (which includes incentive systems, customer segmentation, and the range of products/services offered), describes controller influence on long-term, strategically oriented decisions. These results (at the BU level) are similar to Zoni and Merchant's (2007) findings (at the corporate level).

\subsubsection{Personality traits}

To 'capture' the Five Factor Model, Gosling et al. (2003) developed the Ten Item Personality Inventory (TIPI) instrument. The authors tested the validity of this instrument and found that the ten items it contained constituted a comprehensive representation of the Five Factor Model. We used the TIPTI instrument because of the necessarily limited length of our survey.

Each personality trait consequently consists of two descriptors. Every descriptor uses a common stem: "I see myself as ...". The descriptors are rated on a five-point scale, ranging from 1 (disagree strongly) to 5 (agree strongly). These descriptors are listed in Appendix A. They are labelled EXTRAV, CONSC, STABLE, OPEN, and AGREA (following Section 2.2). A factor analysis with varimax rotation suggested a five-factor solution. These factors explain $73.9 \%$ of the variance in the underlying items. All paired items fit the corresponding personality traits, except for one descriptor ('conventional, uncreative'), which loaded more strongly on factor 1 than on factor 5. Following Howard and Howard (2001) and Gosling et al. (2003), we decided to combine this descriptor with factor 5. By so doing, the five traits became fully in line with the extant literature. 


\subsubsection{Decentralization}

The decentralization instrument stems from Abernethy et al. (2004), who use an adapted version of Gordon and Narayanan's (1984) instrument. Decentralization measures the extent to which a BU has decision-making authority across several types of decisions. The decision areas that Abernethy et al. (2004) distinguish include strategy, investments, marketing, internal processes, and human resource management.

Authorization was measured on a scale ranging from 1 (100\% BU authorization) to 5 (100\% corporate management authorization). These items were reverse coded in our survey (reverse code $=6$ minus actual score) and then factorized. A factor analysis with varimax rotation resulted in one factor, called DECENTR, which explains $46.2 \%$ of the variance in the underlying items. The Cronbach's alpha value of DECENTR is 0.71 .

\subsubsection{Information asymmetry}

Dunk (1993) proposes an instrument to measure information asymmetry between divisional managers and their superiors. We adjusted this instrument to measure information asymmetry between BU controllers and corporate controllers, using six items ranging from 1 (the corporate controller is much more familiar with a BU's business affairs than the BU controller) to 5 (the BU controller is much more familiar with a BU's business affairs). A factor analysis with varimax rotation indicated that one factor, which we call INFOASYM, explains $56.7 \%$ of the variance in the underlying items. The Cronbach's alpha value of INFOASYM is 0.84 .

\subsubsection{Control variables}

Firstly, we controlled for the last year's performance of a BU. This instrument was based on three items taken from Bouwens and van Lent (2007). A factor analysis with varimax rotation yielded one factor, which explains $73.8 \%$ of the variance in the underlying items. This factor is called 'PERFORM'. The Cronbach's alpha value of PERFORM is 0.82 .

Secondly, we controlled for the level of a BU manager's financial knowledge, represented by his/her financial education (Naranjo-Gil et al., 2009). This variable (EDUMGR) was measured by one item. A respondent could select his/her level of financial education using the following categories: $5=$ Certified Public Accountant (CPA) or Executive Master of Finance and Control; 4 = University Master of Science level (MSc); 3 = University Master of Arts (MA), Bachelor level at a regular university (BSc), or Bachelor level at a university of applied sciences (BASc); 2 = upper vocational secondary education in business and administration; and $1=$ other level of education. We based these categories on the Dutch education system.

Thirdly, we controlled for a BU controller's work experience (WRKEXP). BU controllers were asked how many years they had worked (a) for their current organization, (b) as a BU controller and (c) for this BU (in any role). WRKEXP was calculated as the average score across these three items. 
Fourthly, we used the logarithm of the number of employees (in FTE) in the organization as a proxy for its size (LOGSIZE). Finally, as stated in Section 2.4, we added three dummy variables to correct for industry effects: SERVICE $=$ the service sector, PUBLIC $=$ non-profit sector, and FINSERV = financial services. Our base category, for which no dummy variable was defined, contains manufacturing and construction firms.

\section{Results}

\subsection{Research model}

We analyzed the hypotheses in Section 2 using Partial Least Squares (PLS). PLS allows complex models to be estimated with relatively small sample sizes (Verbeeten and Speklé, 2015). It requires fewer assumptions than Ordinary Least Squares (OLS) with respect to multicollinearity, omitted variables bias, and skewed, non-normal distributions of variables (Abernethy and Bouwens, 2005; Verbeeten and Speklé, 2015). In addition, the two levels of perceived controller influence on managerial decisions that we distinguish could be estimated in a single path model.

\subsection{Descriptive statistics}

BU controllers were asked to identify their direct superior: the BU manager or the corporate controller. In 54 cases (45.4\%), the BU manager was the direct/hierarchical superior, and the corporate controller the functional superior of the BU controller. In 16 cases (13.4\%), the corporate controller was a BU controller's only superior, and in 20 cases (16.8\%), the BU manager was his/her only superior. In the other 26 cases $(21.8 \%)$, other superiors, such as the Chief Financial Officer (CFO), were involved, and in 3 cases $(2.5 \%)$ values were missing. On average, BU controllers had nine years of work experience in their current organization. They had held the BU controller position for more than five years. On average, BU controllers had worked in their current BU for a little over three years. Of all 119 controllers, $57.2 \%$ held a Master of Science degree, and 38.7\% a Bachelor of Science (or related) degree. The remaining BU controllers $(4.1 \%)$ had lower levels of education.

Table I presents the descriptive statistics[4] of all the variables used in the PLS analyses. The average scores of STRATPIM (mean =2.42) and OPERPIM (mean =3.27) differ significantly from one another[5]. Therefore, on average, BU controllers seem to influence operating decisions to a greater extent than they do the strategic decisions of their BU managers.

\section{INSERT TABLE I HERE}

Table I shows the average scores of BU controllers' personal characteristics: conscientiousness $($ CONSC, mean $=8.61)$, emotional stability $($ STABLE, mean $=8.21)$, openness $($ OPEN, mean $=8.20)$, extraversion $($ EXTRAV, mean $=6.93)$, and agreeableness (AGREA, mean = 5.67). BU controllers 
appear to have personal traits that make up a distinctive personal profile. They have very high scores on conscientiousness, emotional stability, and openness; they have medium to high scores on extraversion, and they have medium scores on agreeableness.

Table II displays the correlation matrix of the dependent and independent variables in our model. STRATPIM and OPERPIM are significantly, and positively, correlated at the 0.01 level of significance (0.275). The strategic influence of BU controllers (STRATPIM) is also positively related to the degree of decentralization in an organization (DECENTR: 0.242) and the performance of a BU (PERFORM: 0.180). STRATPIM is negatively related to a BU controller's work experience (WRKEXP: -0.173). The influence of a BU controller on operational decisions (OPERPIM) is positively related to his/her openness (OPEN: 0.195) and negatively related to his/her agreeableness (AGREA: -0.220). OPERPIM appears to be less substantive in the service and non-profit sectors than in other sectors (SERVICE: 0.255; PUBLIC: -0.238). We also find that BU managers have a higher level of financial education in larger organizations than in small-sized organizations (EDUMGR: 0.240). In addition, Table II suggests that the independent variables do not exhibit too much multicollinearity (all correlations are below $0.50)[6]$.

\section{INSERT TABLE II HERE}

\subsection{Hypotheses testing}

The assessment of a measurement model in PLS is comparable with principle component analysis. All PLS indicators (which are reported in the tables in Appendix A) are higher than 0.50, which indicates that these items contribute substantially to the PLS model. To assess the reliability of the measurement model, we evaluated the composite reliability (CR) and the average variance extracted (AVE) of our variables. The data in Table I show that composite reliability (CR) is acceptable, because all scores are over 0.80, except for OPERPIM (0.731) and STRATPIM (0.799). The AVE scores of OPERPIM and DECENTR are less than 0.50, which means that convergent validity is relatively low. However, the square root of the AVE scores of all variables turn out be larger than the bivariate correlations between that variable and the other exogenous variables in the model (as can be seen in Table II), indicating substantial discriminant validity (Hair et al., 2016).

Effect sizes can be calculated by means of the f2-statistic. According to Hair et al. (2016, p. 201), f2-values of $0.02,0.15$, and 0.35 signify small, medium, and large effects, respectively. Our f2values range from 0.002 for LOGSIZE and 0.003 for CONSC to $0.163,0.122$ and 0.134 for SERVIC, PUBLIC and FINSERV, respectively. This indicates small to moderate effect sizes for the independent variables under consideration. The effect size of CONSC is by far the lowest of the personality traits included in this study. Hence, we may expect to find no significant relationship between conscientiousness and controller influence. 
Finally, we assessed the predictive quality of our model using the Stone-Geisser (Q2) test (Hair et al., 2016, p. 202). The Q2-values for STRATCIM and OPERCIM are 0.025 and 0.096, respectively. The Q2-value for INFOASYM is 0.080 , and 0.005 for PERFORM. Since all of these values are larger than zero, we can conclude that our model has sufficient predictive relevance, and that it is likely to accurately estimate the latent variables involved.

As Table III shows, STRATPIM is positively related to BU controllers who are extravert (EXTRAV path $=0.152, t=1.451$ ), and positively related to BU controllers who are calm and resilient $($ STABLE path $=0.159, t=1.323)($ Hypotheses 1 and 3). The coefficients of the other personal traits do not differ significantly from zero, so that the expected positive relationship between conscientiousness (path $=-0.025, t=0.259)$ and controller influence on strategic decisions $($ Hypothesis 2 ) is not supported. No relationship is found between agreeableness (path $=0.005, t=0.047$ ), openness (path $=0.025, t=0.220$ ) and STRATPIM[7] (Hypotheses 4 and 5). STRATPIM is positively related to a BU's degree of decentralization (as stipulated in Hypothesis 6, DECENTR path $=0.202, t=1.685$ ). This finding indicates that in cases where decision rights are decentralized to a BU, a BU controller's influence on strategic decisions is larger than in more centralized organizations. The data do not support the relationship between information asymmetry (path $=0.053, t=0.464)$ and STRATPIM (Hypothesis 7).

Table II shows that information asymmetry has a positive correlation with both performance and the degree of $\mathrm{BU}$ decentralization, but no significant correlation with the two types of controller influence. STRATPIM is not significantly related to a BU controller's work experience (WRKEXP path $=-0.106, t=1.150)$ and the industry dummies.

\section{INSERT TABLE III HERE}

Table III also presents the results of the PLS analysis of OPERPIM. We find that OPERPIM is negatively related to BU controllers who are agreeable (AGREA: path $=-0.180, t=1.925$, Hypothesis 4). This finding is not in line with studies by Salgado (1997) and Mount et al. (1998), among others. It suggests that BU controllers who are critical have more influence on the operational decisions taken by their managers than their less critical colleagues. Such a relationship was not found for STRATPIM. The data do not support the other predicted relationships between OPERPIM and EXTRAV (path = $0.075, t=0.731$ ), CONSC (path $=-0.043, t=0.439$ ), STABLE (path $=0.075, t=0.912$ ), and OPEN (path $=0.086, t=0.810)($ Hypotheses 1, 2, 3 and 5).

OPERPIM is positively related to a BU manager's financial education (EDUMGR path $=0.132$, $t=1.450$ ). This result, at the BU level, supports Zoni and Merchant's (2007) finding at the corporate level. However, the data do not support the relationship between decentralization (path $=-0.004, t=$ 0.036) and OPERPIM (Hypothesis 6). This suggests that more decentralization tends to be associated with greater BU controller influence on strategic management decisions, but not on operational 
management decisions. Furthermore, no statistically significant relation between information asymmetry and OPERPIM was found (path $=0.056, t=0.498$ ) (Hypothesis 7). Apparently, BU controllers automatically have more influence on operational decisions, irrespective of their relationship with their BU manager or corporate controller. Our analyses also do not demonstrate a direct relationship between organizational size and both types of controller influence. The coefficients of the industry dummies are all negatively related to OPERPIM at the 0.01 level of significance. Figure II summarizes our results.

\section{INSERT FIGURE II HERE}

\section{Discussion and conclusions}

\subsection{Findings}

The first, major finding of this study concerns controller influence in general. At the BU level, influence has two dimensions: influence on strategic decisions and influence on operational decisions. This difference supports the conclusions formulated by Matějka (2002) and Zoni and Merchant (2007), although they examined controllers at the corporate level. Our analyses also indicate that all BU controllers find that they have some influence on the operational decisions made by their manager(s) (OPERPIM varies from 1.3 to 5.0), but not all BU controllers indicate that they can influence strategic decisions (STRATPIM varies from 1.0 to 4.6). Apparently, influence on operational decisions is easier for controllers to accomplish, perhaps since this is commonly regarded as an important part of their work (Byrne and Pierce, 2007; Zimmerman, 2014). Traditionally, controllers focused on operational tasks, safeguarding the integrity and quality of the (mainly financial) information provided in and by organizations. Despite the automation of many of these tasks by ERP systems and related consolidation packages, controllers still seem to (be required to) do considerable operational work (De Loo et al., 2011). However, their influence now sometimes seems to extend to strategic matters, which were originally the domain of (their) managers (see also Byrne and Pierce, 2007). We cannot claim, however, that all BU controllers have become the 'business partner' of their manager, as is sometimes proclaimed, especially in the professional management literature. Their influence on operational matters would then be negligible - which it is not. We find that most BU controllers fulfil a 'hybrid' role (Burns and Baldvinsdottir, 2005; Byrne and Pierce, 2007; De Loo et al., 2011), focusing on operational as well as strategic decision-making, but to a different extent[8]. BU controllers' work thus tends to be multifaceted (cf. Lambert and Sponem, 2012; Goretzki et al., 2013).

The second group of findings relate to BU controllers' personality traits. BU controllers have high scores on conscientiousness, emotional stability, and openness, medium to high scores on extraversion, and medium scores on agreeableness. These results support the generally held image of controllers as conscientious, calm, unemotional, and resilient professionals (Zimmerman, 2014). 
Still, it is striking that the score on agreeableness is medium instead of low. Someone would expect $\mathrm{BU}$ controllers to frequently challenge their managers, and not to be that agreeable when important business decisions are made. Assuming that the effect of socially desirable answers in our sample is limited (as elaborated in the following section), this could imply that BU managers and BU controllers have worked together for a sufficiently substantial period of time to get used to and accommodate each other's views, so that they know what to expect from one another when important business decisions have to be made. Consequently, it may be that BU managers automatically incorporate their controllers' views in the decisions they make. Given that, on average, BU controllers have held their position for more than five years, this could explain the relatively low score on agreeableness. However, in the case of controllers' perceived influence on operational decisions, it turns out that they cannot be too laid back (as indicated by our results for Hypothesis 4). When controllers are too agreeable in operational affairs, they will become less influential. This finding is in line with results reported by Byrne and Pierce (2007). For STRATPIM, no such relationship was found.

We also found that an increase in decentralization tends to be accompanied by greater BU controller influence on strategic decisions, but not on operational decisions. This supports our idea that influence on operational decisions is something that controllers are commonly expected to exert (Zimmerman, 2014). Whether a controller also becomes engaged in strategic decisions seems to be negotiable, perhaps since this has traditionally been part of his/her manager's work; this manager consequently may not accept or endorse such influence (see also Byrne and Pierce, 2007).

In addition, this study suggests a positive relationship between STRATPIM and extraversion and emotional stability. OPERPIM turned out to be related to critical thinking (low agreeableness), but STRATPIM turned out not to be related. This raises the following questions: do controllers stop being critical when they gain more influence on strategic decisions? If so, then why? Are critical controllers perhaps excluded from exerting influence on strategic decisions? Etc.

We put the view that controllers could become too critical for their managers once they have been allowed to engage in strategic decision-making. Managers may consequently prevent further influence. Another explanation could be related to differences between strategic and operational decision-making processes. When controllers want to influence strategic decisions, they may have to exert influence early on in the decision-making process (before a decision is 'on the table'), since managers may not accept their influence at the stage when a final decision has to be made, because this is perceived to be their task (Byrne and Pierce, 2007). Influencing operational decisions typically happens at a later stage, when decisions are discussed and specific 'facts and figures' have to be prepared to sustain these.

Goretzki et al. (2013) assert that when controllers are willing to have an impact on strategic decisions, and when this is suggested in a way their managers can appreciate, such influence may be granted[9]. However, Lambert and Sponem (2012) state that the possibility to become involved in strategic decision-making is very much dependent on the authority that a particular controller, and the 
controller function as a whole, has in an organization. When authority is substantial, controllers can move beyond carrying out technical tasks and increasingly embrace advisory work - also in strategic matters. Conversely, controllers' involvement may be limited when a defensive attitude is taken by their manager(s). In such cases, it will not help when a controller is also critical. His/her influence may then be further decreased.

A third group of findings relates to organizational factors. As we have seen, positive relationships were found between BU performance and both types of controller influence. We also found a positive relationship between the degree of decentralization and BU controllers' influence on strategic decisions. Thus, decentralization may be a way to increase BU controller's influence on strategic decisions. This study does not support the relationship between OPERPIM and decentralization. Therefore, we claim that a BU controller can always influence operational decisions, regardless of the level of decentralization in his/her organization.

This brings us to answering our main research question: which factors stimulate or hinder BU controllers' influence on managerial decisions taken by their managers? Just like Byrne and Pierce (2007), we propose that BU controllers can partially influence their own role. We refine Byrne and Pierce's conclusions by putting forward two types of influence: on operational and on strategic decisions. In addition, we suggest that there are more opportunities for BU controllers to increase their influence on strategic decisions than on operational decisions. As stated earlier, it should be kept in mind that when BU controllers are asked to engage in strategic decision-making, this may happen at the early stages of the decision-making process, since the strategic decision itself is typically made by their BU manager. Therefore, this type of influence is something that BU controllers have to time well. They cannot apply 'too much' influence 'too late', when a manager feels it is now up to him/her to finalize a decision. Our results suggest that BU controllers could exert considerable influence on strategic decisions when they are calm, conscientious, and constructive, and when they are able to challenge their BU managers in a way that the latter can appreciate. However, we also believe that they cannot be too critical, as this is likely to result in relatively little influence. Organizations could therefore consider selecting more extravert and emotionally stable individuals as BU controllers if they wish to increase the possibility that these controllers will eventually have an impact on strategic decisions. By so doing, it may be that controllers are appointed who are not likely to lose their influence on operational decisions when they are too lenient - at least, in the eyes of their BU manager.

\subsection{Limitations}

This study is subject to a number of limitations. First, we only looked at Dutch organizations and their (domestic) BUs. Second, the study was limited to large, multidivisional organizations. On top of this, we used a convenience sample (cf. Zoni and Merchant, 2007). Future research could try to assess whether our findings remain stable under different conditions. Fourth, the personality traits of BU controllers were limited to those included in the Ten Item Personality Inventory (TIPI) instrument. 
Although this instrument is relatively simple and effective (Gosling et al., 2003), it may be that our results are influenced by self-reporting biases and respondents' tendencies to provide socially desirable answers on these items. This raises the question whether controllers were aware of their generally held self-image when they completed the survey (cf. Zimmerman, 2014), and whether the results reflected their actual beliefs. Although the absence of socially desirable answers cannot be fully guaranteed, we believe there is sufficient variance in the answers with respect to the personality trait items shown in Table I, for instance, and with respect to OPERPIM and STRATPIM to claim that such answers are largely absent. Fifth, this study did not cover personal skills, such as communicative, technical, or interpersonal skills (Rouwelaar, 2015), nor did it analyze interpersonal relationships between BU controllers and BU managers in great detail (Katz and Khan, 1978). Finally, we used Matějka's (2002) instrument to measure controller influence. Thus, we could only assess the perceived influence controllers had on the decisions taken by their managers, and not their actual involvement in these decisions.

\subsection{Future research}

Quantitative studies assessing controllers' degree of influence on managerial decisions are scarce. This study contributes to this body of literature, although it only investigated the perceptions of BU controllers. As was stated above, in order to assess BU controller influence on managerial decisions in greater detail, future studies could include BU managers as respondents, on top of, or instead of, BU controllers (cf. Pierce and O’Dea, 2003; Byrne and Pierce, 2007; Wolf et al., 2015).

More attention could also be devoted to other (not yet tested) factors that might impact on perceived controller influence in management and/or controller involvement in management. Two of these factors are a BU manager's leadership style, and his/her management philosophy. Besides a greater emphasis on the characteristics of BU managers, future research could focus on other organizational factors than the ones included in this study, such as corporate strategy or the impact of ICT developments on the management control system a BU uses.

BU managers can influence BU controllers' performance, but this is also influenced by the way in which BU controllers succeed in influencing and persuading their BU managers (Roozen and Steens, 2006, p. 101; Lambert and Sponem, 2012; Wolf et al., 2015). Future research could investigate how these relations work exactly. This would help in assessing the impact of interpersonal relationships on BU controllers' influence on managerial decisions (Katz and Kahn, 1978). Perhaps more interesting results will be found for STRATPIM than for OPERPIM, as only influence on strategic decisions (STRATPIM) seems to require negotiations and mutual adjustments between BU managers and BU controllers.

More research on the way in which differences between strategic and operational controller influence and/or involvement manifest themselves could help in developing a more solid theoretical framework for perceived controller influence in management and/or controller involvement in 
management (Sathe, 1982) and their consequences for a BU's functioning (Hartmann and Maas, 2010; Weißenberger and Angelkort, 2011; Wolf et al., 2015).

Finally, existing research suggests that management teams ought to include a combination of people with different personality traits to operate effectively (Howard and Howard, 2001). This raises questions about the way in which the inclusion of BU controllers might contribute to the mix of characteristics required to engage in effective decision-making. This could also be assessed in future studies.

\section{Notes}

1. The terms 'controller' and 'management accountant' are used interchangeably throughout continental Europe (Wolf et al., 2015). We will use the term 'controller' from here onward.

2. The Zoni and Merchant (2007) study was conducted at the corporate level instead of the BU level.

3. The opposite of 'emotional stability' is known as 'neuroticism' (Digman, 1990, p. 422).

4. To check for robustness, we also estimated our model with Ordinary Least Squares (OLS) techniques. The results (not tabulated in this paper) were very similar.

5. According to a Mann-Whitney test (Mann-Whitney $\mathrm{U}=3322.5, \mathrm{Z}=-6.766, p=0.000$ ) and a Kolmogorov-Smirnov test (2-tailed: $\mathrm{Z}=3.072, p=0.000$ ).

6. Collinearity statistics indicate that multicollinearity is not a major concern (all VIF-scores are considerably smaller than 10) (Hair et al., 2010).

7. Even though the correlation between OPEN and EXTRAV $(r=0.405)$ is less than 0.50, we decided to control for possible interaction effects between these two variables. The path coefficients (from OPEN to EXTRAV and from EXTRAV to OPEN) are significantly different from zero (path $=0.427, p=0.000$ ). However, the coefficients of the other paths (not included in this paper) are comparable to the ones presented in Table III and Figure II. All conclusions about the hypotheses remain unchanged.

8. We ran a cluster analysis (using Ward's method) based on the items underlying OPERPIM and STRATPIM to check this conclusion (Hair et al., 2010), and found that most of the BU controllers in our sample did indeed have a 'hybrid' role.

9. Pierce and O'Dea (2003) may not agree with this statement. They argue that many controllers appear to be reluctant to become more engaged in business decision-making. 


\section{References}

Abernethy, M.A., Bouwens, J.F.M.G., and Van Lent, L.A.G.M. (2004), "Determinants of Control System Design in Divisionalized Firms", The Accounting Review, Vol. 79, pp. 545-570.

Abernethy, M.A., and Bouwens, J.F.M.G. (2005), "Determinants of Accounting Innovation Implementation", Abacus, Vol. 41 No. 3, pp. 217-240.

Anderson, C., Flynn, F.J., and Spataro, S.E. (2008), "Personality and Organizational Culture as Determinants of Influence", Journal of Applied Psychology, Vol. 93 No. 3, pp. 702-710.

Argyris, C. (1952) "The impact of Budgets on People”, Ithaca: School of Business and Public Administration, Cornell University, New York.

Barrick, M.R., Mount, M.K., and Judge, T.A. (2001), "Personality and Performance at the beginning of the New Millennium: What Do We Know and Where Do We Go Next?", International Journal of election and Assessment, Vol. 9 No.1/2, March/June 2001, pp. 9-30.

Bouwens, J.F.M.G., and Van Lent, L.A.G.M. (2007), "Assessing the Performance of Business Unit Managers", Journal of Accounting Research, Vol. 45 No. 4, pp. 1-31.

Brownell, P. (1983), "Leadership style, Budgetary Participation and Managerial Behavior", Accounting, Organizations and Society, Vol. 8 No. 4, pp. 307-321.

Burns, J., and Baldvinsdottir, G. (2005), “An institutional perspective of accountants' new roles - The interplay of contradictions and praxis", European Accounting Review. Vol. 14 No. 4, pp. 725757.

Burns, J., and Vaivio, J. (2001), "Management Accounting Change", Management Accounting Research, Vol. 12, pp. 389-402.

Byrne, S, and Pierce, B. (2007), "Towards a More Comprehensive Understanding of the Roles of Management Accountants", European Accounting Review, Vol. 16 No 3, pp. 469-498.

Chang, H., Ittner, C.D., and Paz, M.T. (2014), "The Multiple Roles of the Finance Organization: Determinants, Effectiveness, and the Moderating Influence of Information System Integration", Journal of Management Accounting Research, Vol. 26 No. 2, pp. 1-32.

De Loo, I., Verstegen, B.H.J., and Swagerman, D. (2011), "Understanding of the roles of management accountants", European Business Review, Vol. 23 No. 3, pp. 287-313.

Digman, J.M. (1990), "Personality Structure: Emergence of the Big Five-Factor Model”, Annual Review Psychology, Vol. 41, pp. 417-440.

Dunk, A.S. (1993), "The Effect of Budget Emphasis and Information Asymmetry on the Relation between Budgetary Participation and Slack", The Accounting Review, Vol. 68 No. 2, pp. 400410.

Eswaran, S., Islam, Md. A., and Yusuf, D.H.M. (2011), "A Study of the Relationship between the Big Five Personality Dimensions and Job Involvement in a Foreign Based Financial Institution in Penang", International Business Research, Vol. 4 No. 4, pp. 164-175.

Furnham, A., Eracleous, A., and Chamorro-Premuzic, T. (2009), "Personality, motivation and job satisfaction: Hertzberg meets the Big Five", Journal of Managerial Psychology, pp. 765-779.

Gordon, L.A., and Narayanan, V.K. (1984), "Management Accounting Systems, Perceived Environmental Uncertainty and Organization Structure: An Empirical Investigation", Accounting, Organizations and Society, Vol. 9, pp. 33-47.

Goretzki, L., Strauss, E., and Weber, J. (2013), "An institutional perspective on the changes in management accountants' professional role", Management Accounting Research, Vol. 24, pp. 41-63. 
Gosling, S.D., Rentfrow, P.J., and Swann, W.B. (2003), "A very brief measure of the Big-Five personality domains", Journal of Research in Personality, Vol. 37, pp. 504-528.

Hair, J.F., Black, W.C., Babin, B.J., and Anderson, R.E. (2010), “Multivariate Data Analysis a global perspective", $7^{\text {th }}$ edition, Pearson Prentice Hall, New Jersey.

Hair, J.F., Hult, G.T.M. Ringle, Ch.M., and Sarstedt, M. (2016), “A Primer on Partial Least Squares Structural Equation Modeling (PLS-SEM)”, second edition, Sage Publications, London.

Hak, T., Veer, K. Van der, and Jansen, H. (2008), "The Three-Step Test-Interview (TSTI): An observation-based method for pretesting self-completion questionnaires", Survey Research Methods, Vol. 2 No. 3, pp. 143-150.

Harman, H.H. (1976), “Modern Factor Analysis”, $3^{\text {rd }}$ edition, University of Chicago Press, Chicago.

Hartmann, F.G.H., and Maas, V.S. (2010), "Why Business Unit Managers Create Budget Slack: Involvement in Management, Social Pressure, and Machiavellianism", Behavioral Research in Accounting, Vol. 22 No. 2, pp. 27-49.

Howard, P.J., and Howard, J.M. (2001), “The Owner's Manual for Personality at Work: How the Big Five Personality Traits Affect Performance, Communication, Teamwork, Leadership, and Sales", the CentACS, Brad Press.

Indejikian, R.J., and Matějka, M. (2006), "Organizational Slack in Decentralized Firms: The Role of Business Unit Controllers”, The Accounting Review, Vol. 81, pp. 849-872.

Jablonski, S.F., Keating, P.J., and Heian, H.J.B. (1993), "Business Advocate or Corporate Policeman? Assessing Your Role as a Financial Executive”, The Financial Executives Research Foundation, Morristown NJ.

Järvenpää, M. (2007), "Making Business Partners: A Case Study on how Management Accounting Culture was Changed", European Accounting Review, Vol. 16 No. 1, pp. 99-142.

Katz, D., and Kahn, R. (1978). "The social psychology of organizations”, second edition. John Wiley \& Sons, New York.

Lambert, C., and Sponem, S. (2012), "Roles, Authority and Involvement of the Management Accounting Function: A Multiple Case-study Perspective", European Accounting Review, Vol. 21 No. 3, pp. 565-589.

Maas, V.S. (2006), “The effect of Controller Involvement in Management on Performance Measurement System Gaming”, Dissertation at University of Amsterdam, Amsterdam.

Maas, V.S., and Matějka, M. (2009), "Balancing the dual responsibilities of business unit controllers: field and survey evidence", The Accounting Review, Vol. 84 No. 4, pp. 1233-1253.

Matějka, M. (2002), “Management Accounting in Organizational Design: Three Essays”, Dissertation Tilburg University, Tilburg.

Merchant, V., and Stede, W. van der (2012), "Management Control Systems: Performance Measurement, Evaluation and Incentives", third edition, Prentice Hall, Essex, England.

Mount, M.K., and Barrick, M.R. (1998), "Five reasons why the "Big Five" article has been frequently cited”, Personnel Psychology, Vol. 51, pp. 849-857.

Mount, M.K., Barrick, M.R., and Stewart, G.L. (1998), "Five-Factor Model of Personality and Performance in Jobs Involving Interpersonal Interactions", Human Performance, Vol. 11, pp. 145-165.

Moutafi, J., Rurnham, A., and Crump, J. (2007), “Is Managerial Level Related to Personality?", British Journal of Management, Vol. 18, pp. 272-280.

Naranjo-Gil, D., Maas, V.S., and Hartmann, F.G.H. (2009), "How CFOs Determine Management Accounting Innovation: An Examination of Direct and Indirect Effects", European Accounting Review, Vol. 18 No.4, pp. 667-695. 
Pierce, B., and O'Dea, T. (2003), "Management Accounting Information and the needs of managers", The British Accounting Review, Vol. 35, pp. 257-290.

Rouwelaar, J.A. ten (2015), “Business Unit Controller Involvement in Management”, H\&G Uitgeverij, Amsterdam (dissertation Nyenrode Business University).

Roozen, F.A., and Steens, H.B.A. (2006), "Reflections on the Future of Finance and Control”, Kluwer, Deventer.

Salgado, J.F. (1997), "The five-factor model of personality and job performance in the European Community", Journal of Applied Psychology, Vol. 82, pp. 30-43.

Sathe, V. (1982), “Controller Involvement in Management”, Prentice-Hall, New Jersey.

Smith, M. (2015), "Research Methods in Accounting", third edition, SAGE publications, London.

Vaivio, J., and Kokko, T. (2006), "Counting Big: Re-examining the Concept of the Bean Counter Controller", The Finnish Journal of Business Economics, Vol. 55 No. 1, pp. 49-74.

Verbeeten, F.H.M, and Speklé, R.F. (2015), "Management Control, Results-Oriented Culture amd Public Sector Performance: Empirial Evidence on New Public Management", Organization Studies, Vol. 36 no. 7, pp. 953-978.

Weißenberger, B.E., and Angelkort, H. (2011), "Integration of financial and management accounting systems: The mediating influence of a consistent financial language on controllership effectiveness", Management Accounting Research, Vol. 22, pp. 160-180.

Weißenberger, B.E, Angelkort, H., and Holthoff, G. (2013), "MAS Integration and Controllership Effectiveness: Evidence of a Preparer-User Perception Gap", German Academic Association for Business Research, Vol. 5 No. 2, pp. 134-153.

Widener, S.K. (2014), "Researching the human side of management control: using survey-based methods". In: Otley, D., and Soin, K. (Eds.), Management control and uncertainty, Palgrave Macmillan, Basingstoke, pp. 69-82.

Wolf, S., Weißenberger, B.E, Wehner, M.C., and Kabst, R. (2015), "Controllers as business partners in managerial decision-making: Attitude, subjective norm, and internal improvements", Journal of Accounting \& Organizational Change, Vol. 11 No. 1, pp. 24-46.

Zimmerman, J.L. (2014), “Accounting for Decision Making and Control”, eighth edition, McGraw-Hill Higher Education, New York, NY.

Zoni, L., and Merchant, K.A. (2007), "Controller involvement in management: an empirical study in large Italian corporations", Journal of Accounting \& Organizational Change, Vol. 3 No. 1, pp. 29-43. 
APPENDIX A: $\quad$ Survey questions, item level descriptives, factor analysis results, and indicator loadings from PLS

\section{Controller Influence (Matějka, 2002, p. 67)}

Below is a list of items that have an effect on the bottom-line performance of your $B U$.

To what extent can you actually influence what business actions are taken with regard to them?

$(1=$ no influence (my role is to present information and report the results of actions taken by operating managers); $3=$ some influence (my role is to present information and recommend action); $5=$ strong influence (my role is to challenge and modify actions of operating managers)

\begin{tabular}{|c|c|c|c|c|c|c|}
\hline No. & Influence on: & Mean & St. Dev & STRATPIM & OPERPIM & $\begin{array}{l}\text { PLS } \\
\text { indicator }\end{array}$ \\
\hline $\mathrm{C} 1$ & Accounts receivable & 3.38 & 1.285 & 0.181 & 0.606 & 0.723 \\
\hline $\mathrm{C} 2$ & Inventory & 2.78 & 1.317 & -0.092 & 0.759 & 0.785 \\
\hline $\mathrm{C} 3$ & Operating expenses & 3.63 & 0.929 & 0.169 & 0.664 & 0.650 \\
\hline $\mathrm{C} 4$ & Capital expenses & 3.32 & 1.301 & 0.487 & 0.422 & Dropped \\
\hline $\mathrm{C} 5$ & $\begin{array}{l}\text { Incentive systems within your } \\
\text { BU }\end{array}$ & 2.71 & 1.322 & 0.780 & 0.053 & 0.793 \\
\hline C6 & Targeted customer segments & 2.28 & 1.085 & 0.684 & 0.171 & 0.616 \\
\hline $\mathrm{C} 7$ & $\begin{array}{l}\text { Offered range of products or } \\
\text { services }\end{array}$ & 2.25 & 1.047 & 0.753 & 0.027 & 0.844 \\
\hline
\end{tabular}

Personal Characteristics: Ten Item Personality Inventory (Gosling et al., 2003, p. 525)

Please indicate your personal characteristics. I see myself as:

$(1=$ disagree strongly; 2 = disagree a little; $3=$ neither agree nor disagree $; 4=$ agree a little;

$5=$ agree strongly)

\begin{tabular}{lllllllll}
\hline No. & Items: & Mean & St..Dev. & Factor & Factor & Factor & Factor & Factor \\
& & & & 1 & 2 & 3 & 4 & 5 \\
\hline P1 & Extravert, enthusiastic & 3.68 & 1.178 & $\mathbf{0 . 8 1 4}$ & -0.057 & 0.005 & -0.051 & 0.258 \\
P2 & Critical, quarrelsome & 3.96 & 0.969 & -0.120 & 0.017 & $\mathbf{0 . 6 9 4}$ & 0.212 & -0.201 \\
P3 & $\begin{array}{l}\text { Dependable, self- } \\
\text { disciplined }\end{array}$ & 4.18 & 0.863 & -0.106 & $\mathbf{0 . 8 4 0}$ & 0.049 & -0.006 & 0.230 \\
P4 & Anxious, easily upset & 1.82 & 0.983 & 0.046 & 0.002 & 0.011 & $\mathbf{0 . 9 2 7}$ & 0.016 \\
P5 & Open to new experiences, & 4.24 & 0.810 & 0.244 & 0.022 & -0.106 & 0.060 & $\mathbf{0 . 8 6 1}$ \\
& complex & 2.75 & 1.166 & $\mathbf{0 . 8 2 8}$ & -0.194 & 0.139 & -0.061 & -0.070 \\
P6 & Reserved, quiet & 3.63 & 0.882 & 0.059 & 0.027 & $\mathbf{0 . 8 6 0}$ & -0.135 & 0.088 \\
P7 & Sympathetic, warm & 1.57 & 0.869 & 0.011 & $\mathbf{0 . 8 8 9}$ & -0.014 & 0.080 & -0.140 \\
P8 & Disorganized, careless & 4.03 & 0.897 & -0.372 & 0.237 & 0.082 & $\mathbf{0 . 5 2 7}$ & 0.445 \\
P9 & Calm, rational & 4.18 & 0.863 & $\mathbf{0 . 6 8 5}$ & 0.170 & -0.314 & 0.061 & 0.095 \\
P10 & Conventional, uncreative & & & & & & & \\
\hline
\end{tabular}

Calculations: OPEN = P5 + (6 - P10); CONSC = P3 + (6 - P8); EXTRAV = P1 + (6 - P6); AGREA = P7 + (6 - P2); $\mathrm{STAB}=\mathrm{P} 9+(6-\mathrm{P} 4)$. 
Decentralization (Abernethy et al., 2004, p. 564)

Please indicate who can make the following decisions.

( $5=100 \%$ your business unit; $1=100 \%$ (corporate) organization)

\begin{tabular}{llllll}
\hline No: & Items: & Mean & St.Dev. & $\begin{array}{l}\text { Factor } \\
\text { loadings }\end{array}$ & $\begin{array}{l}\text { PLS } \\
\text { indicators }\end{array}$ \\
\hline D1 & $\begin{array}{l}\text { Strategic decisions (e.g., development of } \\
\text { new products; enter and develop new } \\
\text { markets; unit strategy) }\end{array}$ & 1.174 & 0.778 & 0.734 \\
D2 & $\begin{array}{l}\text { Investment decisions (e.g., acquiring new } \\
\text { assets and financing investment projects; } \\
\text { information systems) }\end{array}$ & 1.242 & 0.712 & 0.613 \\
D3 & $\begin{array}{l}\text { Marketing decisions (e.g., campaigns; 3.76 } \\
\text { pricing decisions) } \\
\text { Decision regarding internal processes } \\
\text { (e.g., setting production/sales priorities; } \\
\text { inputs used and/or processes employed to } \\
\text { fill orders; contracting suppliers) }\end{array}$ & 1.231 & 0.944 & 0.759 \\
$\begin{array}{l}\text { Human Resources (e.g., hiring/firing; 3.75 } \\
\text { compensation and setting career paths for } \\
\text { the personnel employed within your unit; } \\
\text { reorganizing your unit; creation of new } \\
\text { jobs) }\end{array}$ & 0.967 & 0.789 & 0.671 \\
D5 & & & & \\
& & & 0.582 \\
\end{tabular}

Information Asymmetry (adapted from Dunk, 1993; Abernethy et al., 2004, p. 565)

We would like some information about the distribution of knowledge between your

$B U$ and the (corporate) organization. $(1=$ corporate controller is much more familiar; $5=I$ am more familiar)

\begin{tabular}{|c|c|c|c|c|c|}
\hline No: & Items: & Mean & St. Dev. & $\begin{array}{l}\text { Factor } \\
\text { loadings }\end{array}$ & $\begin{array}{l}\text { PLS } \\
\text { indicators }\end{array}$ \\
\hline IA1 & $\begin{array}{l}\text { Compared to your Corporate Controller, } \\
\text { who is in possession of better information } \\
\text { regarding the activities undertaken in your } \\
\text { BU? }\end{array}$ & 4.49 & 0.659 & 0.795 & 0.789 \\
\hline IA2 & $\begin{array}{l}\text { Compared to your Corporate Controller, } \\
\text { who is more familiar with the input-output } \\
\text { relationships inherent in the internal } \\
\text { operations of you BU? }\end{array}$ & 4.23 & 0.846 & 0.748 & 0.759 \\
\hline IA3 & $\begin{array}{l}\text { Compared to your Corporate Controller, } \\
\text { who is more certain of the performance } \\
\text { potential of your BU? }\end{array}$ & 4.09 & 0.802 & 0.812 & 0.814 \\
\hline IA4 & $\begin{array}{l}\text { Compared to your Corporate Controller, } \\
\text { who is more familiar technically with the } \\
\text { work of your BU? }\end{array}$ & 4.35 & 0.828 & 0.755 & 0.739 \\
\hline IA5 & $\begin{array}{l}\text { Compared to your Corporate Controller, } \\
\text { who is better able to assess the potential } \\
\text { impact on your activities of factors external } \\
\text { to your BU? }\end{array}$ & 3.66 & 0.888 & 0.619 & 0.760 \\
\hline
\end{tabular}


Performance of your BU (Bouwens and Van Lent, 2007)

Please indicate the performance of your BU: Performance in comparison with external BUs and internal BUs $(1=$ lower than most; $3=$ about average; $5=$ higher than most $)$.

\begin{tabular}{clllll}
\hline No: & Items: & Mean & St.Dev. & $\begin{array}{l}\text { Factor } \\
\text { Loadings }\end{array}$ & $\begin{array}{l}\text { PLS } \\
\text { indicators }\end{array}$ \\
\hline Q1 & $\begin{array}{l}\text { How would you rate last year's } \\
\text { performance of your BU compared } \\
\text { to external firms producing similar } \\
\text { products/services? }\end{array}$ & 1.38 & 0.845 & 0.855 \\
Q2 & $\begin{array}{l}\text { Please rate last year's performance } \\
\text { of your BU against that of other } \\
\text { business units in your organization }\end{array}$ & & 1.57 & & \\
Q3 & $\begin{array}{l}\text { How would you rate last year's } \\
\text { performance of your BU compared } \\
\text { to your superior's expectations? }\end{array}$ & 1.117 & 0.842 & 0.812 \\
& & & & 0.905 \\
\hline
\end{tabular}

